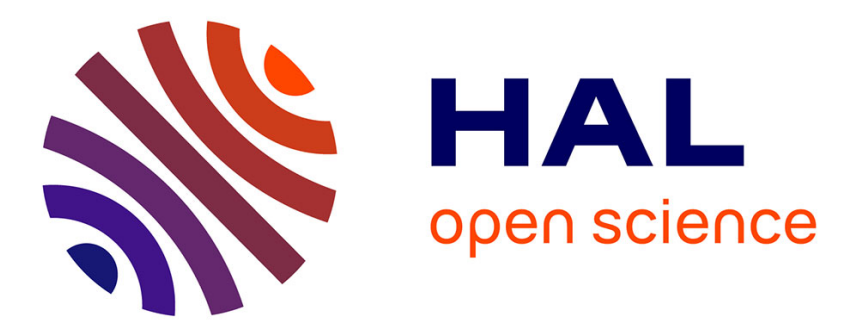

\title{
Failure of the component additivity rule to predict gas yields of biomass in flash pyrolysis at $950^{\circ} \mathrm{C}$
}

\author{
Carole Couhert, Jean-Michel Commandre, Sylvain Salvador
}

\section{To cite this version:}

Carole Couhert, Jean-Michel Commandre, Sylvain Salvador. Failure of the component additivity rule to predict gas yields of biomass in flash pyrolysis at $950^{\circ} \mathrm{C}$. Biomass and Bioenergy, 2009, 33 (2), p.316-326. 10.1016/j.biombioe.2008.07.003 . hal-01846918

\section{HAL Id: hal-01846918 https://hal.science/hal-01846918}

Submitted on 6 Nov 2018

HAL is a multi-disciplinary open access archive for the deposit and dissemination of scientific research documents, whether they are published or not. The documents may come from teaching and research institutions in France or abroad, or from public or private research centers.
L'archive ouverte pluridisciplinaire HAL, est destinée au dépôt et à la diffusion de documents scientifiques de niveau recherche, publiés ou non, émanant des établissements d'enseignement et de recherche français ou étrangers, des laboratoires publics ou privés. 


\section{Failure of the component additivity rule to predict gas yields of biomass in flash pyrolysis at $950^{\circ} \mathrm{C}$}

\section{Carole Couhert*, Jean-Michel Commandré, Sylvain Salvador}

Ecole des Mines d'Albi - Carmaux, Centre RAPSODEE, UMR 2392-CNRS, Campus Jarlard, Route de Teillet 81013, Albi CT Cedex 09, France

Keywords:

Flash pyrolysis

Cellulose

Hemicellulose

Lignin

Biomass

A B S T R A C T

Ligno-cellulosic biomass from different sources presents variable composition. The main aim of this work was to develop a method to predict the gas yields after flash pyrolysis (and tar cracking) at $950^{\circ} \mathrm{C}$ in an Entrained Flow Reactor of any biomass from its composition in the three main components - cellulose, hemicellulose and lignin.

For this approach to be successful, three conditions need to be met:

$\left(C_{1}\right)$ Pyrolytic behaviour of celluloses from different biomasses is similar, as is hemicellulose and lignin behaviour.

$\left(C_{2}\right)$ There is no interaction between the components.

$\left(C_{3}\right)$ Extractives and ashes have no impact on the pyrolysis process.

Two approaches were chosen to investigate the condition $\mathrm{C}_{1}$ :

(i) Celluloses, hemicelluloses and lignins of various sources were pyrolysed. Results show that hemicelluloses and lignins from different sources do not form the same quantities of gases.

(ii) An attempt was made to identify the gas yields of "theoretical components" that are able to predict flash pyrolytic behaviour of any biomass. Results tend to show that this is not possible.

The condition $\mathrm{C}_{2}$ is investigated by comparing the gas yields of the components taken separately and the gas yields of mixes of the components. Two types of mixing were carried out: simple mixing and intimate mixing. Results show that interactions occur between the components during flash pyrolysis.

The condition $C_{3}$ was not investigated here; it can nevertheless be concluded that the behaviour of a biomass during flash pyrolysis at high temperature cannot be predicted from its composition in cellulose, hemicellulose and lignin.

\section{Introduction}

Biomass is today considered as a renewable fuel whose use would help to reduce greenhouse gases, emission. Over the past two decades, worldwide interest has been growing in the

\footnotetext{
* Corresponding author.

E-mail address: couhert@enstimac.fr (C. Couhert).
}

thermochemical conversion of renewable resources through pyrolysis or gasification [1].

There has been great interest in pyrolysis, especially fast pyrolysis of biomass to maximise gas production. Several studies in this field have looked at the effect of experimental 
parameters on products' distribution. For example, Zanzi et al. studied rapid pyrolysis of wood and agricultural residues in a free-fall reactor in the temperature range $750-1000{ }^{\circ} \mathrm{C}$ and determined the effects of heating rate, temperature, particle size and residence time on the product distribution, gas composition and char reactivity. The main gases analysed were $\mathrm{H}_{2}, \mathrm{CH}_{4}, \mathrm{C}_{2} \mathrm{H}_{2}, \mathrm{C}_{2} \mathrm{H}_{4}, \mathrm{C}_{2} \mathrm{H}_{6}, \mathrm{CO}$ and $\mathrm{CO}_{2}$. In the experimental conditions used, the composition of the pyrolysis gases was not significantly influenced by the change in particle size. A higher temperature caused an increase in the total yields of gas and in the proportion of hydrogen [2]. Li et al. carried out the same kind of experiments in the temperature range $500-800^{\circ} \mathrm{C}$. They found that a smaller particle size of biomass and a higher fast pyrolysis temperature tend to produce hydrogen-rich gas [3]. Zabaniotou et al. studied rapid pyrolysis of olive residues at a temperature range from 300 to $600^{\circ} \mathrm{C}$ and heating rates of about $200^{\circ} \mathrm{C} \mathrm{s}^{-1}$. Elevated temperatures and extended volatile residence times seem to enhance secondary reactions leading to higher yields of $\mathrm{CO}$ and $\mathrm{CH}_{4}[4]$.

But biomass is made up of many different varieties which have very different thermal behaviours. The nature and contents of their main constituents - hemicellulose, cellulose and lignin - are different. There is thus a need to develop laboratory tools that are able to predict the thermal and kinetic behaviours of biomasses from their composition.

Most results in this field concern experiments made in Thermo-Gravimetric Analysers (TGA). Rao and Sharma proposed a method in which the pyrolysis reaction is modelled by an $n$ th-order rate equation for components of the biomass and also for the main biomass materials. They found that one can satisfactorily predict experimental data on different biomass materials from the behaviour of their components and from their compositions assuming there is no interaction between them [5]. Gani and Naruse studied the effect of cellulose and lignin contents on pyrolysis and combustion characteristics for several types of biomass. Biomasses and mixtures of cellulose and lignin were heated from 298 to $1173 \mathrm{~K}$ for pyrolysis and to $1088 \mathrm{~K}$ for combustion at a heating rate of $20^{\circ} \mathrm{C} \mathrm{min}{ }^{-1}$. The correlation found between lignin content and reaction conversion would be able to predict the pyrolysis characteristics for any biomass. In fact, lignin mainly controls the decomposition rate during pyrolysis. The morphology of biomasses and simulated biomasses ( $60 \%$ cellulose, $40 \%$ lignin) was different after $1 \mathrm{~h}$ of pyrolysis. Biomasses were still fibrous and porous whereas in simulated biomasses, the lignin remained as a lumpy solid. The combustion of biomasses depends on the char morphology: $\mathrm{O}_{2}$ can diffuse easily inside the particles during real biomass combustion but does not diffuse easily in simulated biomasses [6].

Yang et al. pyrolysed cellulose, hemicellulose and lignin, and synthesized biomass samples containing two or three of the biomass components. Samples were heated to $900^{\circ} \mathrm{C}$ at $10^{\circ} \mathrm{Cmin}^{-1}$. The pyrolysis of the synthesized biomass samples indicated negligible interaction among the three components. A computing approach was made firstly to predict the weight loss of a synthesized biomass from its composition in cellulose, hemicellulose and lignin and secondly to predict the proportions of the three components of a biomass. The calculated results for the weight loss of the synthesized biomass are quite consistent with the experimental results. However, results concerning the prediction of the composition of a biomass in cellulose, hemicellulose and lignin were not very satisfactory [7].

Biagini et al. studied TG-FTIR analysis of lignin-cellulosic biomasses. A constant heating rate of $20^{\circ} \mathrm{C} \mathrm{min}-1$ was used in all the experimental runs, from 105 to $1000^{\circ} \mathrm{C}$. The aim of their work was to apply a weighted sum law (validated in the literature) to the TG results and to validate and extend this law for the profiles (FTIR) of volatile species released. Assuming no interactions between components, composition of biomass in cellulose, hemicellulose and lignin was deduced from experiments. Once the chemical composition of the materials was obtained, a summative law was applied to the release of each gaseous species. The profiles of volatile species released were obtained with good agreement between the experimental results and the calculated values [8].

Some authors have been interested in the pyrolysis of biomasses and in the behaviour of their components in experimental devices different from TGA. Caballero et al. studied the flash pyrolysis of almond shells and their components in a Pyroprobe 1000 between 700 and $900{ }^{\circ} \mathrm{C}$. They found that the almond shell yields obtained with the Pyroprobe 1000 are close to those calculated from the yields from lignin, hemicellulose and cellulose for $\mathrm{CO}$ and $\mathrm{CO}_{2}$, but not always for light hydrocarbons. They studied the decomposition kinetics in a thermobalance too. The thermal global decomposition of almond shells cannot be reproduced by adding up the kinetics of decomposition of their fractions. The authors suggest that there are interactions between components [9].

Hanaoka et al. studied the effect of woody biomass components on air steam gasification using a downdraft fixed-bed gasifier at $1173 \mathrm{~K}$ and at atmospheric pressure. Results suggest that information obtained from the gasification of each component could possibly be used to predict the composition of the product gas generated in air steam gasification of woody biomass. For example, biomasses with a high proportion of lignin produce almost the same quantities of gases as lignins [10].

Di Blasi et al. pyrolysed wood cylinders of different varieties with applied radiation intensities in the range of $28-80 \mathrm{~kW} \mathrm{~m}^{-2}$ in a bench-scale pyrolysis system. Volatile residence times along the heated section were about $6 \mathrm{~s}$. They showed that differences between wood varieties exist due to the different chemical composition and physical structure. The main difference between the pyrolytic behaviour of hardwoods and softwoods is the degradation temperature of lignin which is higher for softwood. Wood varieties with high lignin and/or extractive contents present high char yields and low tar yields. They are preferable for gasification [11].

Li et al. pyrolysed legume straw and apricot stone in a freefall reactor in the temperature range $500-800^{\circ} \mathrm{C}$. They showed that biomass composed of more cellulose and hemicellulose is a better source for hydrogen-rich gaseous production than that composed of lignin [3].

Actually, conclusions are different according to the authors and the experimental conditions. Some authors affirm that it is possible to use linear correlation to predict the thermal behaviour of a biomass from its composition but others show 
that this is not possible. The two classical explanations suggested are the interactions between components and the effect of mineral matter. Few studies have been made on the interactions between components but one can find several works on the influence of mineral matter. Indeed, literature shows that higher is the concentration of minerals in biomass [12-17]:

- higher is the degradation rate;

- lower is the liquid yield;

- higher is the char yield;

- higher is the total gas yield. The $\mathrm{H}_{2}$ and $\mathrm{CO}_{2}$ yields increase while $\mathrm{CH}_{4}$ and $\mathrm{CO}$ yields decrease.

The objective of this paper is to develop a method to predict the gas yields after flash pyrolysis at high temperature $\left(950^{\circ} \mathrm{C}\right)$ of any biomass from its composition. In this work, biomass is seen as an intimate mixing of cellulose, hemicellulose, lignin, extractives and ashes.

In a first approach, the possibility of a correlation between the compositions in $\mathrm{C}, \mathrm{H}$ and $\mathrm{O}$ of biomasses and the gas yields after pyrolysis was explored. Results are not presented in this paper but values of gas yields and percentages of $\mathrm{C}, \mathrm{H}$ and $O$ in biomasses are tabulated in Table 1. They showed that there is no correlation. This can be explained by the fact that thermodynamic equilibrium is not reached in these conditions of pyrolysis. Dupont has shown this in his previous works [18].

The second approach was to try to predict the gas yields of any biomass from its content in the three main components only: cellulose, hemicellulose and lignin, based on the knowledge of the thermal behaviour of each component taken separately. This approach is the core of this study. The conditions for the approach to be successful can be listed as follows:

$\left(C_{1}\right)$ Pyrolytic behaviour of celluloses from different biomasses is similar, as is hemicellulose and lignin behaviour.

$\left(C_{2}\right)$ There is no interaction between the components.

$\left(C_{3}\right)$ Extractives and ashes have no impact on the pyrolysis process.

The investigation of $C_{1}$ is delicate. To deal with this point, two approaches were adopted:

(i) Celluloses, hemicelluloses and lignins of various sources were pyrolysed. (ii) An attempt was made to identify the gas yields of "theoretical components" that are able to predict flash pyrolytic behaviour of any biomass.

The condition $C_{2}$ is investigated by comparing the gas yields of the components taken separately and the gas yields of mixings of the components. To apprehend the effect of the intimacy of the mixing of the components inside biomass, two types of mixings were carried out:

- Simple mixing: in this case, components were not interlocked. Interactions could occur in gas phase only.

- Intimate mixing: in this case, the two components were in contact inside each particle. Interactions between the solids are enabled; interactions between the gases from one component and the other component are favoured inside a particle.

The condition $C_{3}$ is strong but is not investigated here. The reason is that the agent products generally used to eliminate extractives and ashes in biomasses modify the structure of the biomass making the interpretation of results delicate.

\section{Experiments}

\subsection{Experimental device}

The Entrained Flow Reactor (EFR) is described in Fig. 1. It is a $75-\mathrm{mm}$ i.d. and $2 \mathrm{~m}$ long tube into which a $1-\mathrm{m}$ long isothermal reactor is fed with an electrically preheated laminar gas flow. The powdered solid is injected through a water-cooled feeding probe and dispersed over the crosssection of the reactor using a dispersion dome. It is pyrolysed for a controlled residence time before being sampled by a water-cooled probe.

The solid injection consists of a low velocity conveyor belt that ensures an accurate solid mass flow rate. The belt is fed from a V-shaped rail along which a precisely weighted quantity of solid is regularly spread using a calibrated wedge. The gas and solid phases can be collected at different heights (z) using a water-cooled sampling probe, allowing precise control of the different particles and gas residence time. After separating gas from particles, the gases are forwarded to the analysers, via a heated line. The sampled gases are distributed towards four analyser types:

Table 1 - Compositions in C, $\mathrm{H}$ and $\mathrm{O}$ and gas yields after pyrolysis/tar cracking of components and biomasses.

\begin{tabular}{|c|c|c|c|c|c|c|c|c|c|c|}
\hline & & \multicolumn{3}{|c|}{ Ultimate analysis (mass\%) } & \multicolumn{6}{|c|}{ Gas yields (mass\%) } \\
\hline & & $\mathrm{C}$ & $\mathrm{H}$ & $\mathrm{O}$ & $\mathrm{H}_{2}$ & $\mathrm{C}_{2} \mathrm{H}_{4}$ & $\mathrm{C}_{2} \mathrm{H}_{2}$ & $\mathrm{CH}_{4}$ & $\mathrm{CO}$ & $\mathrm{CO}_{2}$ \\
\hline \multirow[t]{3}{*}{ Components } & Microcrystalline cellulose & 42.3 & 6.1 & 51.2 & 2.5 & 3.2 & 1.5 & 5.7 & 51.8 & 7.5 \\
\hline & Xylan from birchwood & 40.6 & 6 & 49.5 & 3.4 & 1.4 & 0.5 & 4.4 & 47.3 & 9.5 \\
\hline & Alkali lignin & 45.8 & 4.5 & 39 & 3.4 & 0.5 & 0.2 & 2.6 & 39.9 & 7.9 \\
\hline \multirow[t]{3}{*}{ Biomasses } & Beechwood & 42.2 & 5.5 & 52.3 & 2.1 & 1.95 & 2.4 & 5.8 & 41.8 & 5.8 \\
\hline & Mix spruce and fir & 45.5 & 5.9 & 48.7 & 2.1 & 1.9 & 2.5 & 5.9 & 38.9 & 5.3 \\
\hline & Rice husk & 40.1 & 5.8 & 39.1 & 1.5 & 1.9 & 2.3 & 4.3 & 25.3 & 4.2 \\
\hline
\end{tabular}




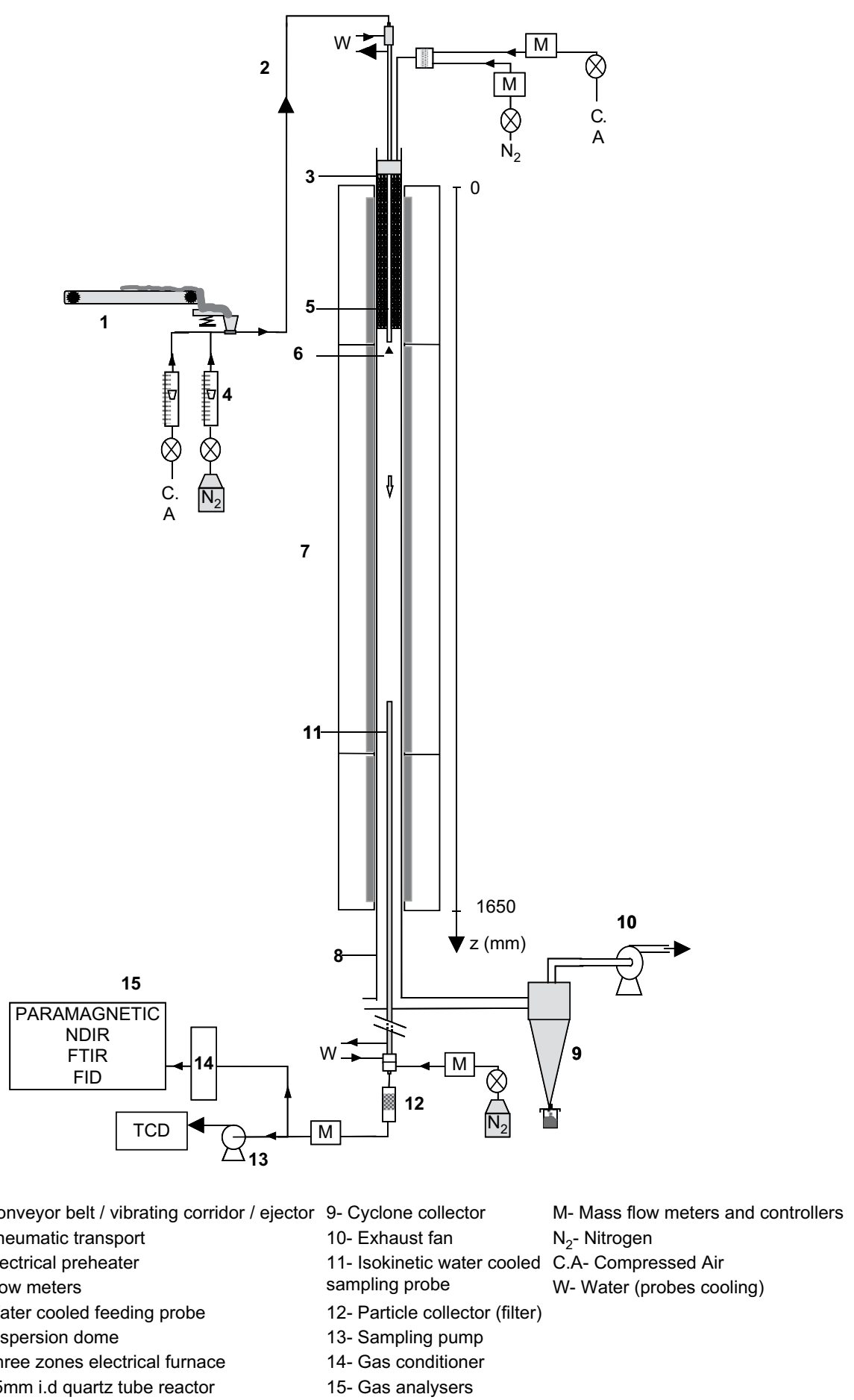

Fig. 1 - Schematic view of the Entrained Flow Reactor of Ecole des Mines d'Albi.

- A Fourier Transform InfraRed (FTIR) analyser to quantify continuously $\mathrm{NO}, \mathrm{NO}_{2}, \mathrm{~N}_{2} \mathrm{O}, \mathrm{NH}_{3}, \mathrm{HCN}, \mathrm{CO}, \mathrm{CO}_{2}, \mathrm{CH}_{4}, \mathrm{C}_{2} \mathrm{H}_{2}$, $\mathrm{C}_{2} \mathrm{H}_{4}, \mathrm{C}_{2} \mathrm{H}_{6}, \mathrm{C}_{3} \mathrm{H}_{8}, \mathrm{C}_{6} \mathrm{H}_{6}$ and $\mathrm{SO}_{2}$.

- A Non-Dispersive InfraRed (NDIR) analyser (for $\mathrm{CO}, \mathrm{CO}_{2}, \mathrm{SO}_{2}$, $\mathrm{NO}$ and $\mathrm{NO}_{x}$ concentrations) coupled with a paramagnetic analyser (for $\mathrm{O}_{2}$ concentration).

- An $\mathrm{H}_{2}$ Thermal Conductivity Detector (TCD).
- A methane analyser, using a Flame Ionisation Detector (FID).

During experiments, $\mathrm{CO}, \mathrm{CO}_{2}, \mathrm{H}_{2}, \mathrm{CH}_{4}, \mathrm{C}_{2} \mathrm{H}_{2}, \mathrm{C}_{2} \mathrm{H}_{4}$ were detected. They are the main gases analysed during pyrolysis and gasification of biomasses and their components by several authors [1-4,9-11]. 
Gas sampling was operated at residence times up to $2.5 \mathrm{~s}$.

The atmosphere gas (nitrogen) and the reactor walls were heated to the controlled temperature of $950^{\circ} \mathrm{C}$. The atmosphere gas plus the solid transport gas flow rate was $14 \mathrm{~L} \mathrm{~min}^{-1}$ (12 $\mathrm{L} \mathrm{min}^{-1}$ for atmosphere gas and $2 \mathrm{~L} \mathrm{~min}^{-1}$ for solid transport gas) at STP; the solid mass flow rate was $1 \mathrm{~g} \mathrm{~min}^{-1}$.

\subsection{Properties of the solids used}

Because commercial hemicellulose cannot be purchased easily, xylan has been widely used as a representative of the hemicellulose component in pyrolysis processes.

The solids used in this work were as follows:

- Two microcrystalline celluloses supplied by Sigma-Aldrich

- "microcrystalline cellulose" (reference: 435236)

- "Sigmacell microcrystalline cellulose" (reference: S5504)

- Three xylans supplied by Sigma-Aldrich

- xylan from birchwood (reference: X0502)

- xylan from beechwood (reference: X4252)

- xylan from oat spelts (reference: X0627)

- Three lignins

- alkali lignin supplied by Sigma-Aldrich (reference: 370959)

- lignin supplied by Meadwestvaco (INDULIN AT, HE08)

- lignin supplied by Borregaard

- Beechwood supplied by Lignex (sample date: June 2005, moisture content: $8.5 \%$ )

- "Spruce and fir" mix supplied by Lignex (sample date: June 2005, content moisture: $7.4 \%$ )

- Rice husk from Camargue (south-east of France) (content moisture: $6.6 \%$ )

Components and biomasses were stored in closed plastic bags, at the temperature of the laboratory and in the absence of light.

Proximate analysis gave the amounts of ash, volatile matter (VM) and fixed carbon (FC=100-\%humidity - \%ashes \%volatile matters) shown in Table 2. The amounts of $\mathrm{C}, \mathrm{H}, \mathrm{N}$ and $\mathrm{S}$ are obtained by ultimate analysis. The amount of oxygen was obtained as the complement to $100 \%$ of C, H, N, S and ash.
C, H, O, N, S compositions are different between components. For example, xylans contain less carbon than celluloses and lignins. Celluloses contain a large quantity of oxygen and hydrogen in comparison with lignins. Proximate analysis is different, and also depends on the components. Celluloses contain no ashes and very few fixed carbon but can form a large quantity of volatile matter during pyrolysis. Lignins contain large quantities of fixed carbon and produce little volatile matter.

More unexpected are the differences inside a family of components. For example, alkali lignin contains 39\% of oxygen while lignin from Meadwestvaco contains $28.3 \%$ of oxygen. Carbon is equal to $45.8 \%$ in alkali lignin and $62.2 \%$ in lignin from Meadwestvaco.

For all products, the fraction of particles with a diameter between 50 and $125 \mu \mathrm{m}$ was selected by pneumatic sieving prior to analysis and experiments. It was checked that the 50$125 \mu \mathrm{m}$ fraction is representative of the original sample from ultimate analysis that showed maximal differences of $0.5 \%$.

\subsection{Preparation of the two-component mixing}

As previously stated, mixing was performed in two ways:

(i) Simple mixing: the products were mixed in equal mass proportion with a spatula in a container. In this case, the particles, once injected in the EFR, maybe in contact but will probably be dispersed in the gas phase. In these conditions, interactions between the gases released by the two types of solids are enabled. The solid residue from one component can also interact with the gases from the other component.

(ii) Intimate mixing: as illustrated in Fig. 2, the components were mixed and then co-ground to thin elements (around $10 \mu \mathrm{m})$. They were then agglomerated with a press and then dispersed with a pestle and mortar to obtain particles around $100 \mu \mathrm{m}$. In this case, the thin elements of the two components are in contact inside a given particle. Interactions between the gases of one component and the solid of the other component are favoured.

Table 2 - Ultimate analysis and proximate analysis of components and biomasses.

\begin{tabular}{|c|c|c|c|c|c|c|c|c|c|}
\hline & & \multicolumn{5}{|c|}{ Ultimate analysis (mass\%) } & \multicolumn{3}{|c|}{ Proximate analysis (mass\%) } \\
\hline & & C & $\mathrm{H}$ & $\mathrm{N}$ & $\mathrm{S}$ & $\mathrm{O}$ & Ashes & Volatile matters & Fixed carbon \\
\hline \multirow[t]{9}{*}{ Components } & Microcrystalline cellulose & 42.3 & 6.1 & 0.3 & 0.1 & 51.2 & 0 & 95.1 & 0.1 \\
\hline & Microcrystalline & 42.3 & 5.9 & 0.3 & 0.1 & 51.4 & 0 & 94.4 & 0.7 \\
\hline & Sigmacell cellulose & & & & & & & & \\
\hline & Xylan from birchwood & 40.6 & 6.0 & 0.2 & 0 & 49.5 & 3.7 & 75.9 & 14.7 \\
\hline & Xylan from beechwood & 38.3 & 5.7 & 0.3 & 0 & 51.3 & 4.4 & 77.5 & 13.3 \\
\hline & Xylan from oat spelts & 37.4 & 5.5 & 0.04 & 0 & 47.7 & 9.4 & 73.2 & 19.6 \\
\hline & Alkali lignin & 45.8 & 4.5 & 0.4 & 1.3 & 39 & 9 & 55 & 35 \\
\hline & Lignin from Borregaard & 50.1 & 5 & 0.5 & 0.6 & 31.8 & 12 & 50.9 & 38.2 \\
\hline & Lignin from Meadwestvaco & 62.2 & 5.7 & 1.0 & 0.5 & 28.3 & 2.3 & 60.7 & 34.8 \\
\hline \multirow[t]{3}{*}{ Biomasses } & Beechwood & 42.2 & 5.5 & 0.03 & 0 & 52.3 & 0.5 & 85.6 & 5.3 \\
\hline & Mix spruce and fir & 45.5 & 5.9 & 0 & 0 & 48.7 & 0.4 & 84.2 & 8 \\
\hline & Rice husk & 40.1 & 5.8 & 0.7 & 0.05 & 39.1 & 14.2 & 58 & 21.7 \\
\hline
\end{tabular}




\section{Results and discussion}

\subsection{Condition $C_{1}$ : similarity in the thermal behaviour of components from all biomasses}

\subsubsection{Pyrolysis of components taken separately}

Experiments with pyrolysis were first run with microcrystalline cellulose, xylan from birchwood and alkali lignin. We recall here that - given the reaction temperature of $950^{\circ} \mathrm{C}-$ two reactions are expected to occur: devolatilisation of the components and tar cracking. The temperature is too low for char gasification in the residence time conditions [12].

The time evolution of the gas yields, on a dry ash-free basis, is presented in Fig. 3 for the three components. After a time period of $0.5-1 \mathrm{~s}$, the gas yields appear not to change significantly with time. Pyrolysis can be considered as finished over these short residence times in agreement with results found by Dupont. Moreover, it seems that the gas phase cracking reactions stop forming permanent gas after these short residence times. It is not possible from the present results to determine accurately from what time the pyrolysis and tar cracking are over; this is not the scope of the work.

Roughly speaking, $\mathrm{CO}$ is the main gas species formed, with $36-60 \%$ of the initial component. The species $\mathrm{CO}_{2}$ is produced in quantities from 4.7 to $14 \%, \mathrm{CH}_{4}$ is produced in quantities from 2.8 to $6.5 \%$ and $\mathrm{H}_{2}$ in quantities from 2 to $5 \% . \mathrm{C}_{2} \mathrm{H}_{4}$ and $\mathrm{C}_{2} \mathrm{H}_{2}$ are produced in minor quantities. The total mass of gas species represents $60-85 \%$ of the mass of the component depending on which component is pyrolysed. Hereafter, results will be presented only for the longest residence time.

Feeding a regular mass flow rate of powdered solid fuel and sampling part of it can be seen as a delicate operation and potential source of experimental errors. In order to validate results obtained and to evaluate how far they are dependent on the reactor used to operate the pyrolysis, complementary experiments were made that varied in the experimental conditions. The solid mass flow rate, the atmosphere gas flow rate and the transport gas flow rate were varied during the pyrolysis of microcrystalline cellulose. Five types of experiments were carried out and repeated. Fig. 4 shows mass yields of three main gases: $\mathrm{CO}, \mathrm{H}_{2}$ and $\mathrm{CH}_{4}$ after pyrolysis of microcrystalline cellulose under different conditions. Results are quite repeatable. Type 1 experiments correspond to the reference conditions. The uncertainty in gas yield measurement can be evaluated by examining the repeatability for type 1 experiments. It can be estimated at around $4 \%$ for $\mathrm{CO}, 9 \%$ for $\mathrm{H}_{2}$ and $4 \%$ for $\mathrm{CH}_{4}$. Considering these uncertainties, there are very little differences between gas yields when the gas flow rates and the solid flow rate are changed. A light difference can be observed for $\mathrm{CH}_{4}$ in type 3 experiments, which produce less $\mathrm{CH}_{4}$ than others but it remains negligible. These complementary experiments enable us to conclude that the experiments carried out in this work are not affected by the operating parameters, and can be considered as representative for flash pyrolysis at $950^{\circ} \mathrm{C}$.

The idea here was simply to characterize the thermal behaviour of cellulose, hemicellulose and lignin from different sources and to quantify the differences observed among a same component family. Two celluloses, three hemicelluloses and three lignins were described previously and used in this study.

Pyrolysis of all celluloses, hemicelluloses and lignins was then carried out. All experiments were repeated several times. The results are reported in Fig. 5. For all components, uncertainties are lower than $8 \%$ of the values for main gases like $\mathrm{CO}$, $\mathrm{CH}_{4}$ and $\mathrm{H}_{2}$. For $\mathrm{CO}_{2}$ and minor gases like $\mathrm{C}_{2} \mathrm{H}_{4}$ and $\mathrm{C}_{2} \mathrm{H}_{2}$, uncertainties are greater and can reach $25 \%$ of the values. These gases are relatively unstable in our conditions of pyrolysis.

In the case of the two celluloses, there are no or few differences between gas yields.

For lignins, Fig. 5 shows that an average of $2.1 \%$ of hydrogen is formed by lignin from Meadwestvaco while $4.5 \%$ is formed by alkali lignin and lignin from Borregaard. An average of $30.3 \%$ of carbon monoxide is formed by lignin from Meadwestvaco while $49.3 \%$ is formed by alkali lignin pyrolysis. For the lignin from Meadwestvaco, low amounts of $\mathrm{NH}_{3}$ $(0.4 \%)$ and $\mathrm{C}_{6} \mathrm{H}_{6}(3.9 \%)$ were quantified, though this was not the case for the others.

As regards xylans, Fig. 5 shows that an average of $1.8 \%$ of hydrogen is formed by xylan from oat spelts while $3.9 \%$ is formed by xylan from birchwood pyrolysis. Similarly, an average of $38.5 \%$ of carbon monoxide is formed by xylan from oat spelts while $54 \%$ is formed by xylan from beechwood pyrolysis. It can be concluded that xylans from different origins can form very different quantities of a given gas species.

From these results, it is clear that one cannot talk about the gas yield of "Hemicellulose" or "Lignin" without referring to a particular Hemicellulose or a particular Lignin. However, it is interesting to note that xylans of the two woods - beechwood and birchwood - have almost the same pyrolytic behaviour: no or few differences are observed between the analysed quantities for all gases.

Fig. 6 groups together the average values (of repeatability experiments) for all the characterized components. Differences are observed between the components but are often less important than differences inside a family of components.
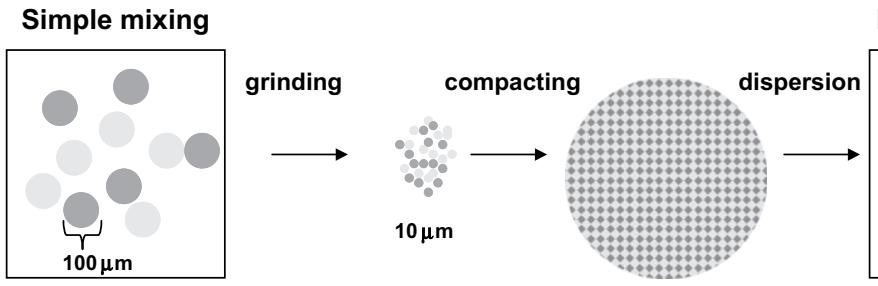

Intimate mixing

Fig. 2 - Simple and intimate mixings. 


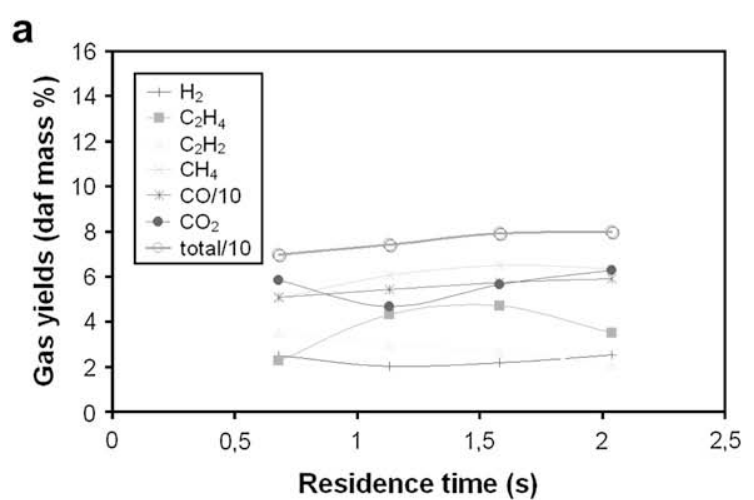

\section{b}

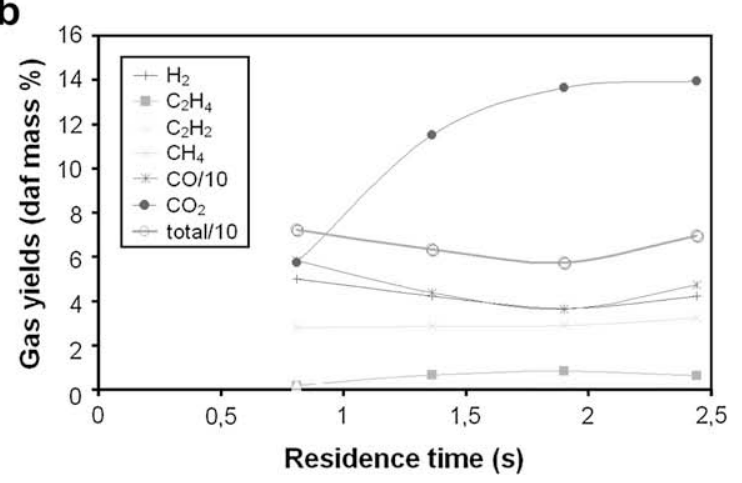

\section{C}

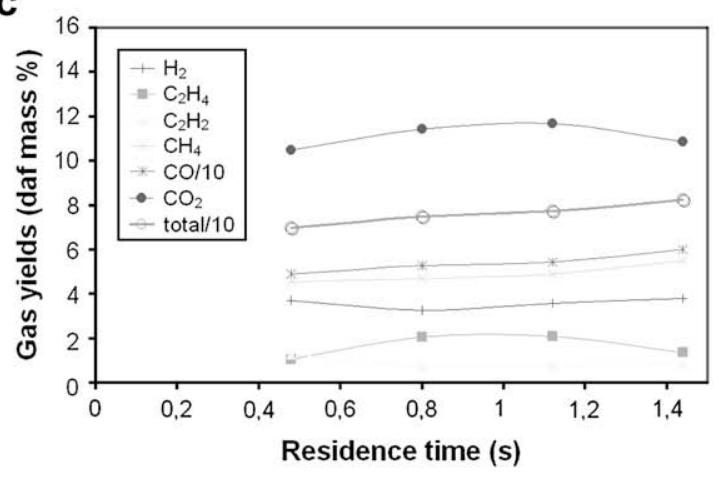

Fig. 3 - Time evolution of yields during pyrolysis of microcrystalline cellulose (a), alkali lignin (b) and xylan from birchwood (c) at $950^{\circ} \mathrm{C}$. The $\mathrm{CO}$ yields and total yields are divided by 10 .

These results show that it is not possible to predict pyrolytic behaviour of any biomass from its composition in cellulose, hemicellulose and lignin. But it is not excluded to be able to predict pyrolytic behaviour of a given type of biomass, such as wood, from its composition in cellulose, hemicellulose and lignin. For this, xylans and lignins from woods will certainly have to be chosen. This paper does not examine this possibility but it might be an interesting path to follow.

We recall that these differences between components' gas yields could perhaps not only be explained by the origin of the components but may also be the result of the extraction process. In fact, in extraction process, chemical products are used that can modify the structure of a component of the biomass and also modify the type and the quantities of gases produced during pyrolysis.
3.1.2. Search for gas yields of "theoretical components" If conditions $C_{2}$ and $C_{3}$ are fulfilled, then the gas yields of each theoretical component can be identified on the basis of experiments carried out with different biomasses containing different proportions in cellulose, hemicellulose and lignin.

Three biomasses have been chosen for this study:

- Two woods:

- Beechwood

- "Spruce and fir" mix

- Rice husk

It is difficult to determine accurately the composition in cellulose, hemicellulose and lignin of a biomass because of the multitude of current extraction processes. Average compositions found in literature were adopted and shown in Fig. 7. The "spruce and fir" mix contains more cellulose and lignin than the other biomasses; rice husk contains larger quantities of hemicellulose.

Gas yields of biomass pyrolysis are shown in Fig. 8. Quantities of gases formed during pyrolysis are different depending on biomasses, mostly for CO that is produced in smaller quantity with rice husk.

If theoretical components exist, their gas yields must match the following system of equations for each gas:

$$
\begin{aligned}
& Y_{\text {beechwood }}=\alpha_{1} Y_{\text {cellulose }}+\alpha_{2} Y_{\text {hemicellulose }}+\alpha_{3} Y_{\text {lignin }} \\
& Y_{\text {spruce and fir }}=\beta_{1} Y_{\text {cellulose }}+\beta_{2} Y_{\text {hemicellulose }}+\beta_{3} Y_{\text {lignin }} \\
& Y_{\text {rice husk }}=\gamma_{1} Y_{\text {cellulose }}+\gamma_{2} Y_{\text {hemicellulose }}+\gamma_{3} Y_{\text {lignin }}
\end{aligned}
$$

with $\mathrm{Y}=$ gas yield of a biomass or a "theoretical component" for one gas.

$\alpha_{1}, \beta_{1}, \gamma_{1}=$ mass proportion of cellulose in beechwood, spruce and fir and rice husk, respectively.

$\alpha_{2}, \beta_{2}, \gamma_{2}=$ mass proportion of hemicellulose in beechwood, spruce and fir and rice husk, respectively.

$\alpha_{3}, \beta_{3}, \gamma_{3}=$ mass proportion of lignin in beechwood, spruce and fir and rice husk, respectively.

An interesting visualisation of the results obtained is proposed in Fig. 9. Any biomass can be located in the base triangle with pure components cellulose $(\mathrm{C})$, hemicellulose $(\mathrm{H})$ and lignin (L) at the vertexes. The content of a biomass in one component corresponds with the value read on the corresponding axis after perpendicular projection. In ordinate are plotted the gas yields (a: $\mathrm{CO}, \mathrm{b}: \mathrm{H}_{2}, \mathrm{c}: \mathrm{CH}_{4}, \mathrm{~d}: \mathrm{CO}_{2}$ ). The results obtained with the pure components have been plotted (on the vertical lines above $\mathrm{C}, \mathrm{H}$ and $\mathrm{L}$ ). One retrieves that the gas yields of different hemicelluloses are very different, and the same for the different lignins.

Considering alternatively the highest values and the lowest values of the gas yields for pure component, one can plot two planes (dotted lines) limiting the domain in which the yield for any biomass should fall in if an additivity law applies. The figures show that it is the case for several biomasses and several gases, but that in some cases the results are very far away from the domain, as underlined by the full lines. 


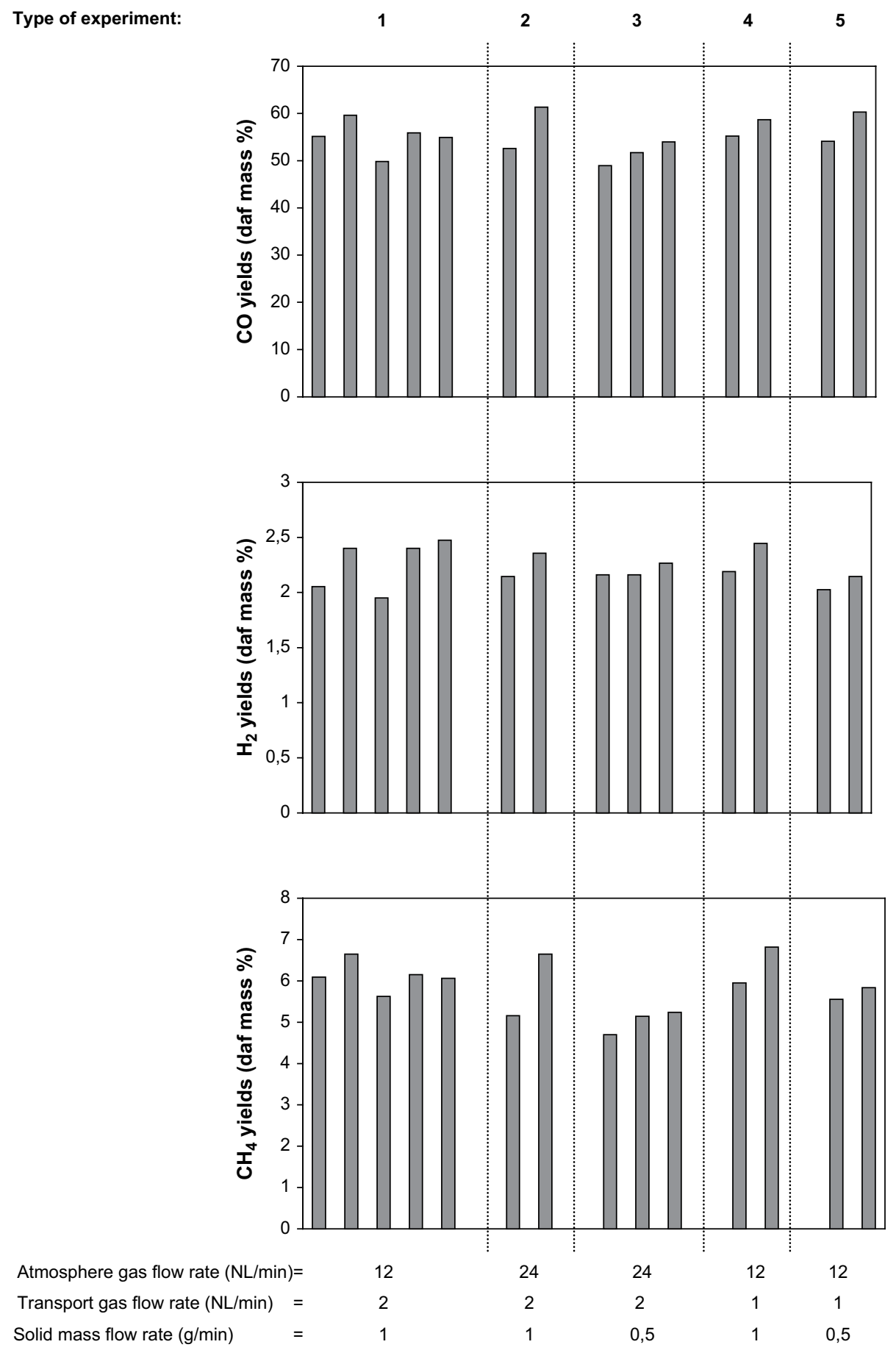

Fig. 4 - Yields of $\mathrm{CO}, \mathrm{H}_{2}$ and $\mathrm{CH}_{4}$ for several conditions of pyrolysis at $950{ }^{\circ} \mathrm{C}$ for cellulose.

In another approach, if an additivity law applies, the gas yields for the three biomasses should lie in a plane whose intersection with the vertical lines above $\mathrm{C}, \mathrm{H}$ and $\mathrm{L}$ would define the gas yields of "theoretical" pure components. If one plots this plane, the intersections sometimes occur at negative values for the gas yields of the "theoretical" pure components, which is not an acceptable solution. Nevertheless, the three biomasses used here have quite similar compositions in $\mathrm{C}, \mathrm{H}$ and $\mathrm{L}$, and there is an uncertainty in the values of their composition. As a consequence, no clear conclusion can be drawn at this stage. Nevertheless, it is clear that the present results are far from a simple situation corresponding with an additivity situation, which would be characterized by all gas yields - for the pure components and for the three biomasses - lying in the same plane.

A perspective to this work would be to experiment biomass with compositions in $\mathrm{C}, \mathrm{H}$ and $\mathrm{L}$ very different from the three present biomasses, like bark and grass. 


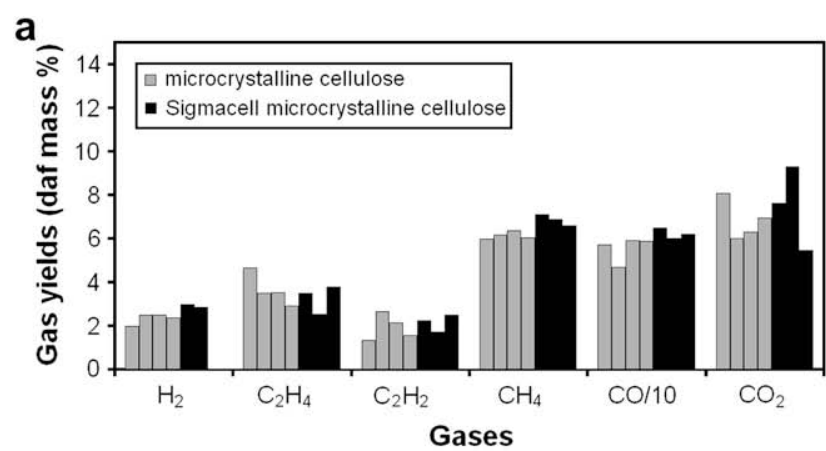

b
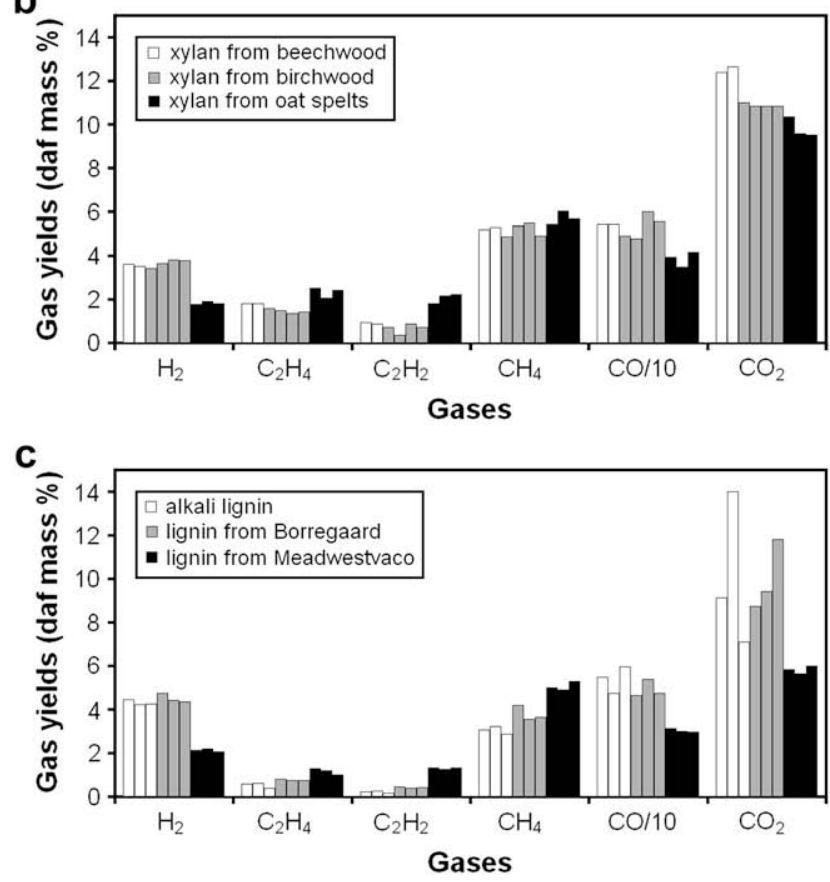

Fig. 5 - Gas yields from two different celluloses (a), three different xylans (b) and three different lignins (c) pyrolysed at $950^{\circ} \mathrm{C}$ for $2 \mathrm{~s}$.

Finally, the two approaches used to investigate the similarity of cellulose, hemicellulose and lignin in all biomasses tend to show that at least one of the conditions, $C_{1}, C_{2}$ and $C_{3}$, is not verified.

\subsection{Investigation of interactions between components: condition $\mathrm{C}_{2}$}

For these experiments, microcrystalline cellulose, alkali lignin and xylan from birchwood were first characterized separately. They were then mixed in two-component mixes, and this in two ways: the simple mixing and the intimate mixing as detailed before.

If no interactions occur, the gas yields of a mixture should be the mass-weighted average yields of the two components following:

$\mathrm{Y}_{\text {mix }}=\alpha \mathrm{Y}_{\mathrm{c} 1}+(1-\alpha) \mathrm{Y}_{\mathrm{c} 2}$

where $\alpha$ is mass fraction of the component 1 in mixing, $Y_{\text {mix }}$ is

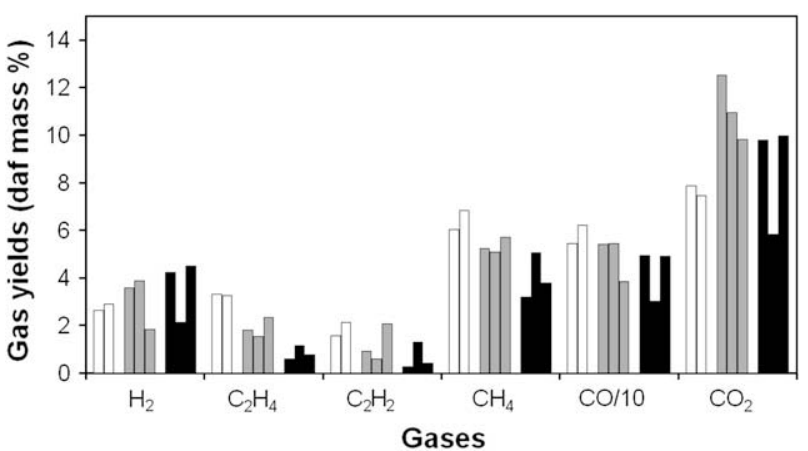

Fig. 6 - Gas yields from all the components at $950^{\circ} \mathrm{C}$. From left to right: white: microcrystalline cellulose and Sigmacell microcrystalline cellulose; grey: xylan from beechwood, xylan from birchwood and xylan from oat spelts; black: alkali lignin, lignin from Meadwestvaco and lignin from Borregaard.

gas yield of the mixing, $Y_{\mathrm{c} 1}$ is gas yield of the component 1 and $\mathrm{Y}_{\mathrm{c} 2}$ is gas yield of the component 2 .

The intimacy of the mixing might play a role on the interactions between the components. In order to take this into consideration, the differences between gas yields calculated with Eq. (4) and gas yields analysed during pyrolysis of simple and intimate mixings (described previously) have been plotted. Results - not presented here - have shown that it is difficult to conclude because of uncertainties (mean deviations obtained by repeating experiments three to five times) that are sometimes larger than observed difference. However, in certain cases, for the gas species $\mathrm{CO}_{2}, \mathrm{H}_{2}$ and $\mathrm{CH}_{4}$, clear differences are observed between experimental yields and calculated yields. As an example, Fig. 10 represents the $\mathrm{CO}_{2}$ yields calculated with Eq. (4) and the $\mathrm{CO}_{2}$ yields measured during pyrolysis of simple and intimate mixings. Results show that for the three mixings (cellulose-lignin, cellulose-xylan and lignin-xylan), the yield of $\mathrm{CO}_{2}$ for intimate mixing is significantly different from the yield of $\mathrm{CO}_{2}$ for simple mixing and from calculated yield. In the cases of the cellulose-lignin (a) and cellulose-xylan (b) mixings, the yield of $\mathrm{CO}_{2}$ for the

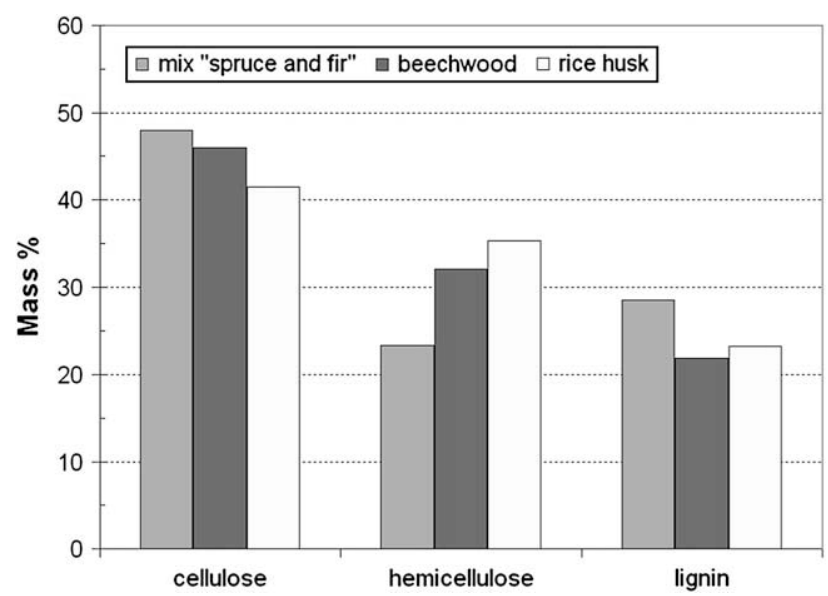

Fig. 7 - Mass percentage of each component in biomasses. 


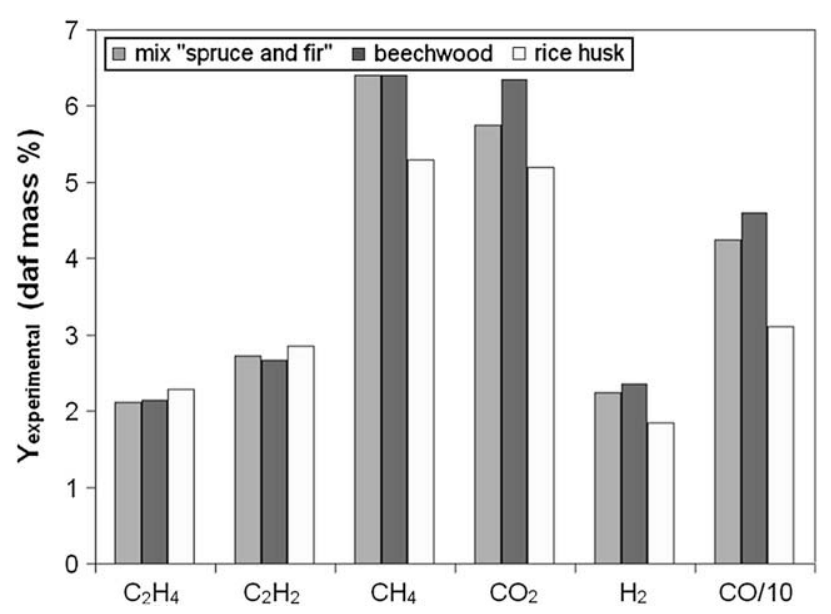

Fig. 8 - Gas yields from the three biomasses pyrolysed at $950^{\circ} \mathrm{C}$.

simple mixing is larger than the calculated yield. The difference between the experimental yield and the calculated yield is still larger in the case of intimate mixing. In the case of the lignin-xylan mixing (c), the yield of $\mathrm{CO}_{2}$ for simple mixing is slightly lower than the calculated yield. The difference between the experimental yield and the calculated yield is larger in the case of intimate mixing. These results indicate that interactions occur between components during pyrolysis. The intimacy of the mixing plays a role on the process.

Because of this, the quantities of gases formed during flash pyrolysis of mixes at high temperature cannot be predicted by a simple weight sum law. It should be noted that the components in real biomass are mixed in a very complex way. In a wood, for example, cellulose is concentrated inside the fibre and the external walls of the fibre are composed essentially of lignins and hemicelluloses. Lignins combine fibres between themselves and hemicelluloses combine celluloses with lignins. The presence of pectins increases the complexity of the matrix [19].

We recall that the amounts of gas species observed in this work are not only the result of the pyrolysis of the solids, but also of tar cracking. Conclusions about interactions do not apply to pyrolysis alone but to the sequence pyrolysis/tar cracking. It should also be mentioned that it was checked that the procedure of grinding, compacting and dispersion of a given component does not affect its gas yields during pyrolysis/tar cracking.

\section{Conclusions}

The gas yields of a biomass after pyrolysis/tar cracking at $950{ }^{\circ} \mathrm{C}$ tend to stabilise after $0.5-1 \mathrm{~s}$. The quantities obtained are not correlated to the $\mathrm{C}, \mathrm{H}$ and $\mathrm{O}$ atoms' content of the biomass.

From the different approaches adopted in this work trying to correlate the contents of cellulose, hemicellulose and lignin with the gas yields, a number of conclusions can be drawn:

(i) The gas yields of two celluloses from different origins are very similar. This is far from being the case for the gas
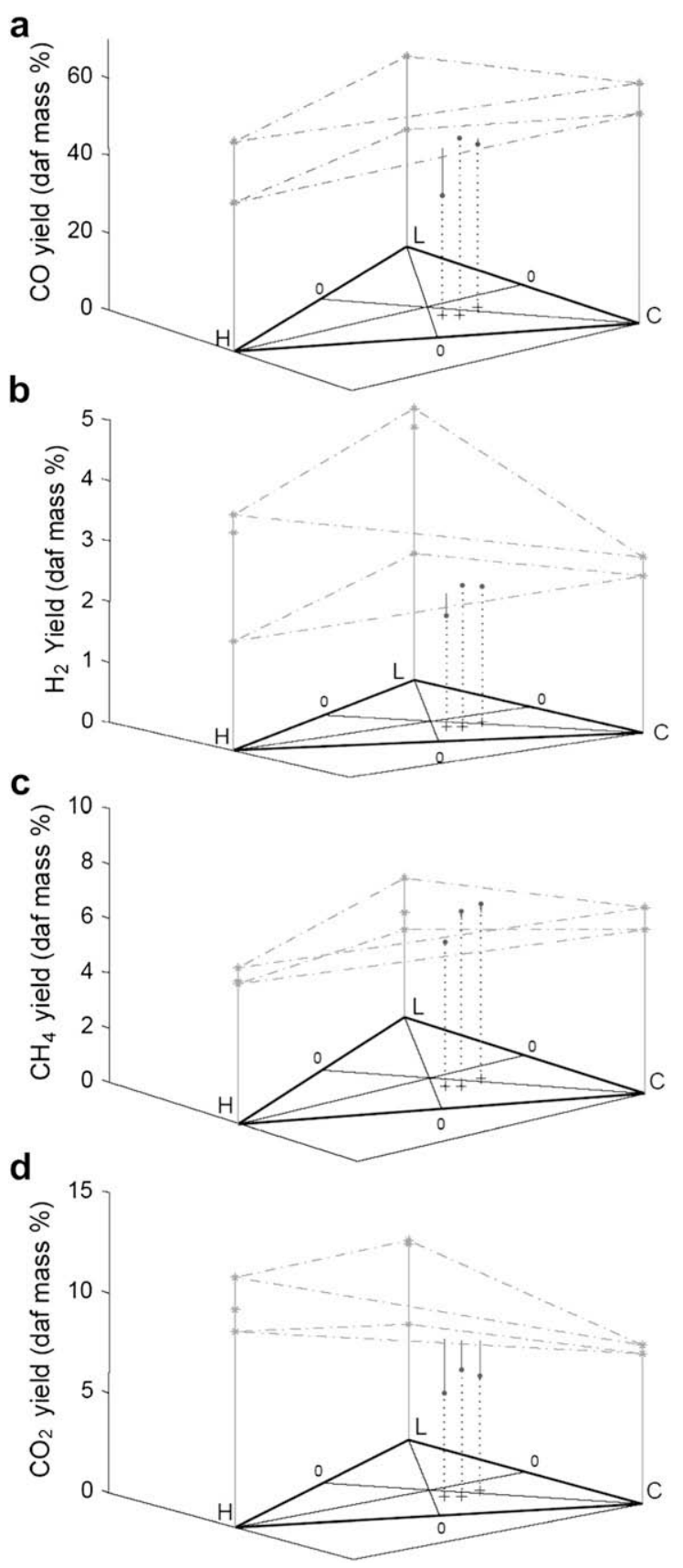

Fig. 9 - Visualisation of the gas yields of biomasses and components: (a) $\mathrm{CO}$, (b) $\mathrm{H}_{2}$, (c) $\mathrm{CH}_{4}$, (d) $\mathrm{CO}_{2}$.

yields of different hemicelluloses, or for the gas yields of different lignins. It is difficult from these results to draw any conclusions in terms of the actual difference of component as found inside biomasses because the treatment used to extract the components from the biomasses is different from one supplier to another, and is likely to affect the structure of the components.

(ii) It is not possible to identify the gas yields of a "theoretical cellulose", a "theoretical hemicellulose" and a "theoretical lignin" from which the gas yields of three biomasses can be predicted by a weighted sum law. This indicates that cellulose, hemicellulose and lignin in the different 

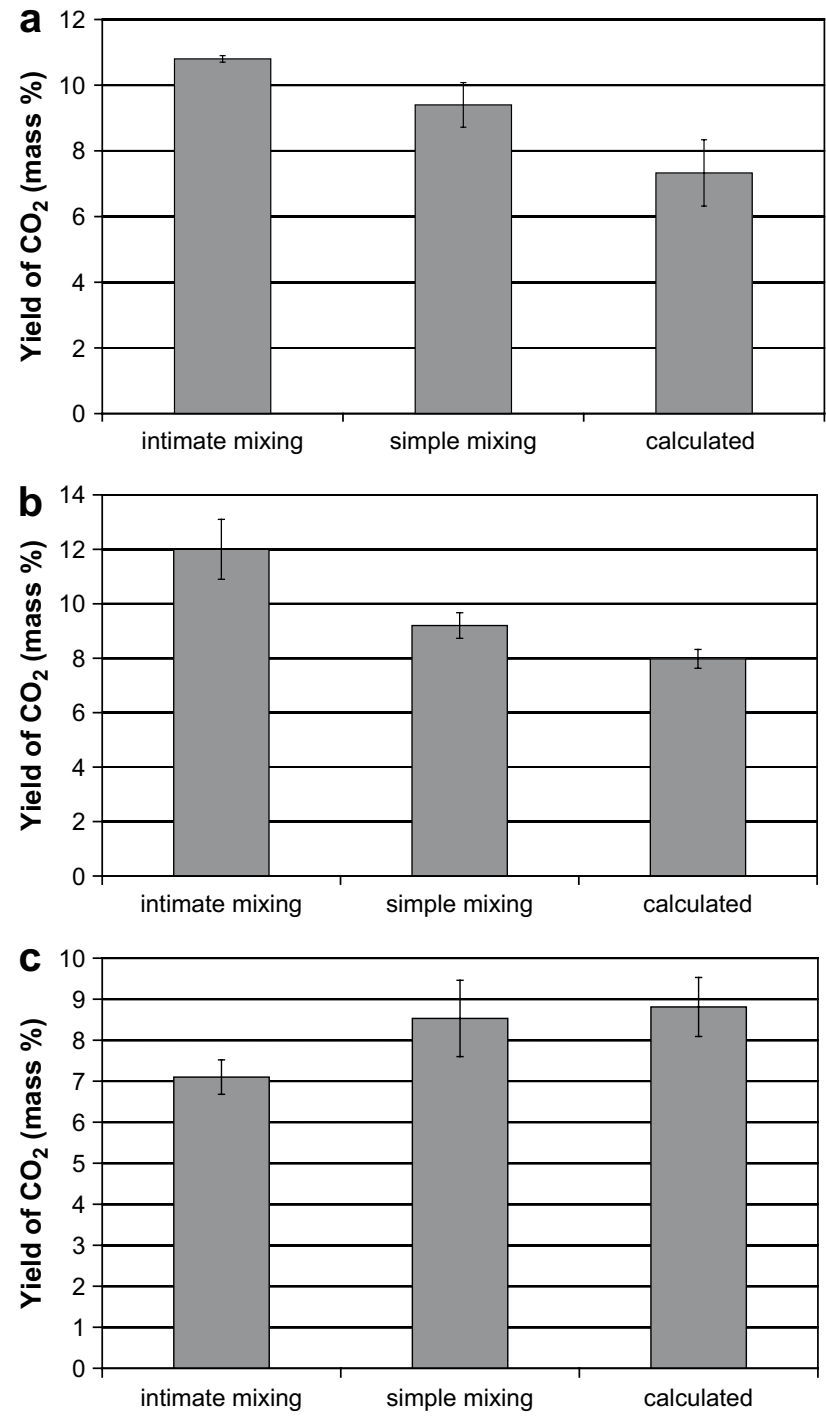

Fig. $10-\mathrm{CO}_{2}$ yields for simple mixings and intimate mixings and calculated yields: (a) cellulose-lignin, (b) cellulose-xylan and (c) xylan-lignin.

biomasses have different behaviours during pyrolysis, or that extractives - and more likely ashes - have an impact on the process.

(iii) There are interactions between the components during flash pyrolysis and tar cracking at high temperature. This was established with experiments of pyrolysis of simple mixings and intimate mixings (scale of $10 \mu \mathrm{m}$ ); it is understood that "mixing" of the components is still more intimate in a real biomass but if interactions occur during the pyrolysis of mixings, they will certainly occur during the pyrolysis of real biomasses.

It can be concluded from this work that it is not possible to predict the gas yields of any biomass during flash pyrolysis at high temperature only from the knowledge of its composition in cellulose, hemicellulose and lignin or in $\mathrm{C}, \mathrm{H}$ and $\mathrm{O}$.

\section{R E F E R E N C E S}

[1] Ferdous D, Dalai AK, Bej SK, Thring RW, Bakhshi NN. Production of $\mathrm{H}_{2}$ and medium Btu gas via pyrolysis of lignins in a fixed-bed reactor. Fuel Process Technol 2001;70:9-26.

[2] Zanzi R, Sjöström K, Björnbom E. Rapid high-temperature pyrolysis of biomass in a free-fall reactor. Fuel 1996;75(5): $545-50$.

[3] Li S, Xu S, Liu S, Yang C, Lu Q. Fast pyrolysis of biomass in a free-fall reactor for hydrogen-rich gas. Fuel Process Technol 2004;85:1201-11.

[4] Zabaniotou AA, Kalogiannis G, Kappas E, Karabelas AJ. Olive residues (cuttings and kernels) rapid pyrolysis product yields and kinetics. Biomass Bioenergy 2000;18:411-20.

[5] Rajeswara Rao T, Sharma A. Pyrolysis rates of biomass materials. Energy 1998;23(11):973-8.

[6] Gani A, Naruse I. Effect of cellulose and lignin content on pyrolysis and combustion characteristics for several types of biomass. Renewable Energy 2007;32:649-61.

[7] Yang H, Yan R, Chen H, Zheng C, Lee DH, Liang DT. In-depth investigation of biomass pyrolysis based on three major components: hemicellulose, cellulose and lignin. Energy Fuels 2006;20:388-93.

[8] Biagini E, Barontini F, Tognotti L. Devolatilization of biomass fuels and biomass components studied by TG/FTIR technique. Ind Eng Chem Res 2006;45:4486-93.

[9] Caballero JA, Font R, Marcilla A. Comparative study of the pyrolysis of almond shells and their fractions, holocellulose and lignin. Product yields and kinetics. Thermochim Acta 1996;276:57-77.

[10] Hanaoka T, Inoue S, Uno S, Ogi T, Minowa T. Effect of woody biomass components on air-steam gasification. Biomass Bioenergy 2005;28:69-76.

[11] Di Blasi C, Branca C, Santoro A, Hernandez EG. Pyrolytic behavior and products of some wood varieties. Combust Flame 2001;124:165-77.

[12] Di Blasi C, Branca C, D'Errico G. Degradation characteristics of straw and washed straw. Thermochim Acta 2000;364:133-42.

[13] Yang H, Yan R, Chen H, Zheng C, Lee DH, Liang DT. Influence of mineral matter on pyrolysis of palm oil wastes. Combust Flame 2006;146:605-11.

[14] Das P, Ganesh A, Wangikar P. Influence of pretreatment for deashing of sugarcane bagasse on pyrolysis products. Biomass Bioenergy 2004;27:445-57.

[15] Nik-Azar M, Hajaligol MR, Sohrabi M, Dabir B. Mineral matter effects in rapid pyrolysis of beech wood. Fuel Process Technol 1997;51:7-17.

[16] Bru K, Blin J, Julbe A, Volle G. Pyrolysis of metal impregnated biomass: an innovative catalytic way to produce gas fuel. J Anal Appl Pyrolysis 2007;78:291-300.

[17] Vamvuka D, Troulinos S, Kastanaki E. The effect of mineral matter on the physical and chemical activation of low rank coal and biomass materials. Fuel 2006;85:1763-71.

[18] Dupont C. Vapogazéification de la biomasse: Contribution à l'étude de la phénoménologie entre $800^{\circ} \mathrm{C}$ et $1000^{\circ} \mathrm{C}$. $\mathrm{PhD}$ thesis 2006, Université Claude Bernard - Lyon 1; 2006.

[19] Rousset P. Choix et validation expérimentale d'un modèle de pyrolyse pour le bois traité par haute température: de la micro-particule au bois massif. PhD thesis 2004, Ecole Nationale du Génie Rural des Eaux et des Forêts; 2004. 